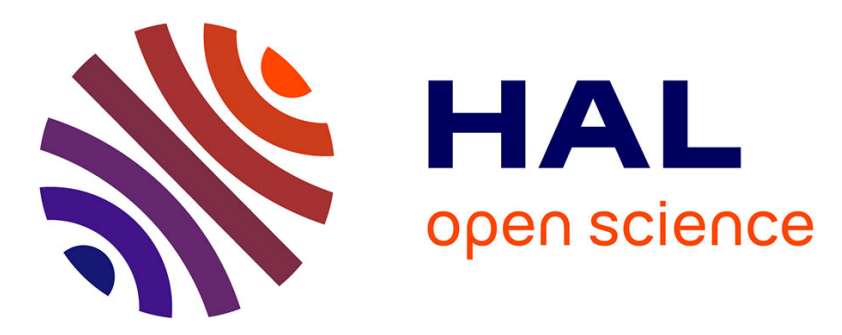

\title{
Estimation of the fatigue strength distribution in high-cycle multiaxial fatigue taking into account the stress-strain gradient effect
}

Thomas Delahay, Thierry Palin-Luc

\section{- To cite this version:}

Thomas Delahay, Thierry Palin-Luc. Estimation of the fatigue strength distribution in high-cycle multiaxial fatigue taking into account the stress-strain gradient effect. International Journal of Fatigue, 2006, 28, pp.474-484. 10.1016/j.ijfatigue.2005.06.048 . hal-01368381

\section{HAL Id: hal-01368381 \\ https://hal.science/hal-01368381}

Submitted on 19 Sep 2016

HAL is a multi-disciplinary open access archive for the deposit and dissemination of scientific research documents, whether they are published or not. The documents may come from teaching and research institutions in France or abroad, or from public or private research centers.
L'archive ouverte pluridisciplinaire HAL, est destinée au dépôt et à la diffusion de documents scientifiques de niveau recherche, publiés ou non, émanant des établissements d'enseignement et de recherche français ou étrangers, des laboratoires publics ou privés. 


\title{
Estimation of the fatigue strength distribution in high-cycle multiaxial fatigue taking into account the stress-strain gradient effect
}

\author{
Thomas Delahay, Thierry Palin-Luc* \\ ENSAM CER de Bordeaux, Laboratoire Matériaux Endommagement Fiabilité et Ingénierie des Procédés (LAMEFIP), \\ EA 2727, Esplanade des Arts et Métiers, F-33405 Talence Cedex, France
}

\begin{abstract}
Based on the weakest link concept, a probabilistic approach in high-cycle multiaxial fatigue is developed to predict, for a given number of cycles, the probability distribution of the fatigue strength for metallic structural components. A three-parameter Weibull distribution is combined with the energy-based and volumetric high-cycle multiaxial fatigue criterion proposed by Banvillet et al. in 2002 [Banvillet A, Palin-Luc T, Lasserre S. A volumetric energy based high cycle multiaxial fatigue criterion. Int J Fatigue 2003;26(8):755-69; Banvillet A, Palin-Luc T, Lasserre S, Vittori JF. Energy based high cycle multiaxial fatigue criterion depending on stress-strain distribution. In: Blom AF, editor. Fatigue 2002: eighth international fatigue congress, vol. 1, EMAS: Stockholm; 2002, p. 283-90]. Whatever the stress state and the loading type are, the corresponding fatigue strength probability distribution can be deduced from three usual experimental fatigue limits. The scale effect is also predicted. Experimental probability distributions and theoretical predictions of the fatigue strength of smooth specimens are in good agreement for the five materials investigated: the 30NiCrMo16 and 35CrMo4 quenched and tempered steels, the C20 annealed steel, the EN-GJS800-2 nodular cast iron and the Ti-6Al-4V titanium alloy.
\end{abstract}

Keywords: High-cycle multiaxial fatigue; Weibull; Energy; Criterion; Probability; Volume

\section{Introduction}

Most of the multiaxial fatigue criteria commonly used in fatigue design are deterministic, and their parameters are identified from experimental fatigue limits for a failure probability of $50 \%$. They cannot take into account the wellknown statistical nature (large scatter) of the high-cycle fatigue strength. Furthermore, in high-cycle fatigue, the notch effect and the influence of the load type on the fatigue strength are well known, too (for instance, the endurance limits in tension or in plane bending or in rotative bending are different). A reliable fatigue calculation method should consider both the volumetric distribution of stresses and the load type. To take into account the stress gradient and the load type effects, Banvillet et al. [1,2] proposed a deterministic energy-based high-cycle multiaxial fatigue criterion using the concept of volume influencing fatigue crack initiation. A usual statistical

\footnotetext{
* Corresponding author. Tel.: +33 55684 5360; fax: +33 556845366 .

E-mail address: thierry.palin-luc@lamef.bordeaux.ensam.fr

(T. Palin-Luc).
}

approach (i.e. the weakest link concept, already used by Bomas [3], Hild [4], Chantier [5] and Flacelière [6]) is hereafter combined with the deterministic volumetric energy-based criterion proposed in Refs. [1,2].

The weakest link concept applied to a volume of material was proposed by Weibull in 1939 [7,8] to describe the scatter of the quasi-static strength of brittle materials. Later, this was extended to the fatigue strength by Freudenthal [9]. Its basic assumption is the existence of statistically distributed defects in the volume of the material. Furthermore, this theory is based on the following main hypotheses:

- the structure is considered as a link series;

- the failure of the weakest link generates the fracture of the whole structure;

- there is no interaction between defects (i.e. the distance between defects is supposed to be much larger than their characteristic size).

According to these hypotheses, for a structure with a volume $V$, the weakest link concept allows us to write the life probability, $P_{\mathrm{L}}$, of the structure under the uniaxial stress $\sigma$ as a function of the life probabilities of all the elementary volumes 


\begin{tabular}{|c|c|c|c|}
\hline \multicolumn{4}{|c|}{ Nomenclature } \\
\hline$A$ & elongation after failure in quasi-static tension & $\beta$ & material parameter of the volumetric energy-based \\
\hline $\begin{array}{l}C_{i} \\
\mathrm{~d} T\end{array}$ & triaxiality degree of stresses & $\nu$ & $\begin{array}{l}\text { proposal } \\
\text { Poisson ratio }\end{array}$ \\
\hline$E$ & Young modulus & $\sigma_{\mathrm{a}}$ & normal stress amplitude \\
\hline$F(\mathrm{~d} T, \beta)$ & $\begin{array}{l}\text { correction function depending on the triaxiality } \\
\text { degree of stresses }\end{array}$ & $\begin{array}{l}\bar{\sigma} \\
\sigma^{*}\end{array}$ & $\begin{array}{l}\text { mean value of the normal stress } \\
\text { threshold stress }\end{array}$ \\
\hline $\begin{array}{l}\vec{n} \\
R\end{array}$ & $\begin{array}{l}\text { unit vector normal to a material plane } \\
\text { specimen radius }\end{array}$ & $\sigma_{\text {Ten, }-1}^{\mathrm{D}}$ & $\begin{array}{l}\text { fully reversed endurance limit in tension on smooth } \\
\text { specimen }\end{array}$ \\
\hline $\begin{array}{l}R_{\sigma} \\
\text { REP }\end{array}$ & $\begin{array}{l}\text { load ratio } \sigma_{\min } / \sigma_{\max } \\
\text { relative error of prediction }\end{array}$ & $\sigma_{\text {RotBen,-1 }}^{\mathrm{D}}$ & $\begin{array}{l}-1 \text { fully reversed endurance limit in rotating bending } \\
\text { on smooth specimen }\end{array}$ \\
\hline $\begin{array}{l}R_{\mathrm{m}} \\
s\end{array}$ & $\begin{array}{l}\text { maximum tensile strength in quasi-static tension } \\
\text { standard deviation of the fatigue limit }\end{array}$ & $\sigma_{\mathrm{PBen},-1}^{\mathrm{D}}$ & $\begin{array}{l}\text { fully reversed endurance limit in plane bending on } \\
\text { smooth specimen }\end{array}$ \\
\hline$s_{\text {Tens, }-1}$ & $\begin{array}{l}\text { standard deviation of the fatigue limit in fully } \\
\text { reversed tension }\end{array}$ & $\begin{array}{l}\sigma_{\mathrm{y}} \\
\tau_{\mathrm{a}}\end{array}$ & $\begin{array}{l}\text { yield stress in quasi-static tension } \\
\text { shear stress amplitude }\end{array}$ \\
\hline$T$ & loading period & $\bar{\tau}$ & value of the mean shear stress \\
\hline $\begin{array}{l}V_{\mathrm{e}} \\
V^{*}\end{array}$ & $\begin{array}{l}\text { elementary volume of material } \\
\text { volume influencing fatigue crack initiation }\end{array}$ & $\tau_{-1}^{\mathrm{D}}$ & $\begin{array}{l}\text { fully reversed endurance limit in torsion on smooth } \\
\text { specimen }\end{array}$ \\
\hline$W_{\mathrm{g}}$ & $\begin{array}{l}\text { strain work density given to the material per } \\
\text { loading period }\end{array}$ & & $\begin{array}{l}\text { yield stress in quasi-static torsion } \\
\text { phase shift for combined loadings }\end{array}$ \\
\hline$W_{\mathrm{g}}^{*}$ & threshold value of $W_{\mathrm{g}}$ corresponding to $\sigma^{*}$ & $\sum(M$ & stress tensor at point $M$ (function of time) \\
\hline
\end{tabular}

of material $V_{\mathrm{e}, i}$, by the following equation:

$P_{\mathrm{L}}(V, \sigma)=\prod_{i=1}^{i=k} P_{\mathrm{L}}\left(V_{\mathrm{e}, i}, \sigma\right)$

The weakest link theory supposes that life probabilities of two disjoined elementary volumes, $V_{\mathrm{e}, 1}$ and $V_{\mathrm{e}, 2}$, are independent. The life probability of the sum of such two volumes is then given by:

$P_{\mathrm{L}}\left(V_{\mathrm{e}, 1}+V_{\mathrm{e}, 2}\right)=P_{\mathrm{L}}\left(V_{\mathrm{e}, 1}\right) \cdot P_{\mathrm{L}}\left(V_{\mathrm{e}, 2}\right)$

When the sizes of the elementary volumes tend to zero, the weakest link model gives us the following distribution to describe the failure probability of a series of links with random threshold stresses [10]

$$
\begin{aligned}
P_{\mathrm{F}}(V) & =1-P_{\mathrm{L}}(V)=1-\exp \left[\sum_{i} \varphi_{i} V_{\mathrm{e}, i}\right] \\
& =1-\exp \left\{-\int_{V} \varphi(x, y, z) \mathrm{d} V\right\}
\end{aligned}
$$

where $\varphi_{i}$ characterizes the failure probability of each elementary volume $V_{\mathrm{e}, i}$, and $\varphi(x, y, z)$ is the spatial concentration function of the failure probability of the material, which depends on the stress $\sigma$. Its analytical expression was introduced by Weibull [9]

$\varphi(x, y, z)=\frac{1}{V_{0}}\left(\frac{\left\langle\sigma-\sigma_{0}\right\rangle}{\sigma_{u}}\right)^{m}$

where $\langle a\rangle=a$ if $a>0$ and $\langle a\rangle=0$ if $a \leq 0$.

According to Weibull $[7,8]$, such a failure probability is given by

$P_{F}(V, \sigma)=1-\exp \left[-\frac{1}{V_{0}} \int_{V}\left(\frac{\left\langle\sigma-\sigma_{0}\right\rangle}{\sigma_{u}}\right)^{m} d V\right]$

where $\sigma_{0}$ is a threshold stress below which there is no damage, $\sigma_{\mathrm{u}}$ is a scale parameter, $V_{0}$ is a reference volume, $m$ is the Weibull slope.

This formalism has been used by several authors to predict the probability distribution of the fatigue strength. The approach by Bomas et al. [3] is based on a relation between the distribution of the size of defects in the material and the failure probability. These authors distinguish the fatigue crack initiation on the surface and in the core of material. They consider that the effects (on the fatigue life) of the defects on the surface and in the core of the material are different from each other, and must be computed separately. The Dang Van criterion [11] is used by Bomas et al. to define an equivalent stress amplitude which is combined to the weakest link concept in order to define life probabilities on the surface and in the volume.

According to Hild [4] and Chantier [5], the fatigue strength of cast parts is generally reduced by the presence of initial casting flaws that are more or less randomly distributed within the material. Under cyclic loading conditions, microcracks propagate from these initial flaws. An element of volume is assumed to contain initial flaws randomly distributed. The cumulative failure probability is defined as the probability of finding flaws greater than a critical size after a number of cycles.

Flacelière et al. [6] have proposed an extension of the nonlocal criterion developed by Morel and Palin-Luc [12,13]. They distinguish the fatigue crack initiation on the surface and 
in the volume of material. The weakest link concept is combined with the criterion presented in Ref. [6] in order to predict, for a given number of cycles, the probability distribution of the fatigue strength for metallic materials. Predictions of the model are in good agreement with the median endurance limits (for $10^{6}$ cycles or more) but the predicted scatters are not in good agreement with experimental scatters. This can be explained by the fact that the model parameters are identified from median endurance limits only, whereas the scatter of any experiments is not considered. To the knowledge of the present authors, none of the probabilistic methods from the literature takes into account the stress-strain gradient effect and the load type effect. The main aim of the present paper is to take into account such effects.

\section{Probabilistic and volumetric high-cycle fatigue approach}

In the following, the failure of a structural component with a volume $V$ is assumed to occur as the fatigue crack initiates. The characteristic size of this fatigue crack is typically $1 \mathrm{~mm}$. This corresponds to a 'technical fatigue crack' which can be detected in real time on an automatic fatigue testing machine by monitoring the specimen (or component) stiffness decrease. This means that fatigue macrocrack propagation is not taken into account in this paper.

\subsection{Threshold stress and volume influencing fatigue crack initiation}

Fatigue tests in loading blocks carried out on smooth specimens of spheroidal graphite (SG) cast iron, submitted to fully reversed plane bending and torsion [14-16], prove that blocks with a stress amplitude below the conventional endurance limit $\sigma^{\mathrm{D}}$ and above a threshold stress amplitude, $\sigma^{*}$ participate to damage. More recently, this was confirmed by Delahay [17] on a titanium alloy. At a given instant, a stress amplitude below $\sigma^{*}$ does not initiate observable damage at the microscale (no microcracks). Between $\sigma^{*}$ and $\sigma^{\mathrm{D}}$, the stress amplitude only contributes to microdamage initiation if, either near this point or in the course of time, there is a stress amplitude higher than the endurance limit. The usual endurance limit, $\sigma^{\mathrm{D}}$, is a limit of no damage propagation but it is not a limit of no damage initiation at the microscale. Several works show that microcracks could initiate but not propagate up to macrocracks on a specimen loaded at its endurance limit. The threshold stress $\sigma^{*}$ can be estimated $[1,18]$ from the endurance limits on smooth specimens under fully reversed tension and rotating bending:

$\sigma^{*}=\sqrt{2\left(\sigma_{\mathrm{Ten},-1}^{\mathrm{D}}\right)^{2}-\left(\sigma_{\mathrm{RotBend},-1}^{\mathrm{D}}\right)^{2}}$

At the moment, the $\sigma^{*}$ probability distribution is not known; that is the reason why, in first approximation, this threshold stress is considered as a deterministic parameter in the present paper. SEM observations of a specimen loaded at a stress level higher than this limit show quick microcrack initiation, and this microcrack does not propagate if the stress amplitude stays below the usual endurance limit.

More recently [19], sinusoidal plane bending fatigue tests have been carried out on specimens with a square crosssection, made of spheroidal graphite (SG) cast iron. SEM observations of the specimen lateral faces, where there is a stress gradient, show microdamaged areas. Microcracks are observed in areas loaded at stress levels above a threshold stress which corresponds well to the threshold stress $\sigma^{*}$ identified from experiments by loading blocks. Then, these observations show that there is a microdamaged volume around the fatigue critical point. With the hypothesis that the whole damaged volume, $V^{*}$ participates to the macrocrack initiation (engineering scale), a criterion should take into account stress and strain distributions inside this volume. All the local fatigue criteria (using the tensor of stresses or strains at the critical point only) cannot distinguish the endurance limits corresponding to different load types. The stress gradient effect is not predicted by these criteria because the distribution of stresses around this point is not taken into account. By using this threshold stress $\sigma^{*}$, Palin-Luc and Lasserre [18] and Banvillet et al. [1] proposed a volumetric energy-based high-cycle multiaxial fatigue criterion. To predict the effect (on the fatigue strength) of the stress-strain distribution inside the component, they considered the volume $V^{*}$ influencing fatigue crack initiation. For a fully reversed uniaxial stress state, this volume is defined by the set of points loaded by a stress amplitude higher than the material dependent threshold stress $\sigma^{*}$.

For any multiaxial stress state, Banvillet et al. [1] proposed a damage parameter given by the strain work density per loading cycle with the period $T, W_{\mathrm{g}}$ (at point $M$ of the material)

$W_{\mathrm{g}}(M)=\sum_{i} \sum_{j} \int_{T}\left\langle\sigma_{i j}(M, t) \dot{\varepsilon}_{i j}^{\mathrm{e}}(M, t)\right\rangle \mathrm{d} t$

where $\langle a\rangle=a$ if $a>0$ and $\langle a\rangle=0$ if $a \leq 0 ; \dot{\varepsilon}=\mathrm{d} \varepsilon / \mathrm{d} t$.

This proposal is based on the hypothesis that no microdamage can initiate and grow, from microscale to macroscale, without giving a certain amount of strain work in each elementary volume of material $[1,19]$. The parameter $W_{\mathrm{g}}$ is calculated with the elastic strains after elastic shakedown of the material. In high-cycle fatigue, the stresses are low enough to consider that the material remains elastic at the macroscopic scale after elastic shakedown, which is supposed to occur to reach long life [20]. Furthermore, it has to be noticed that $W_{\mathrm{g}}$ is not load shape dependent (this parameter has the same value under sinusoidal or triangular tension; see Ref. [1] for details). The threshold work $W_{\mathrm{g}}^{*}$ corresponding to the stress limit $\sigma^{*}$ is defined with reference to an homogeneous fully reversed uniaxial stress state (tension on smooth specimen): $W_{\mathrm{g}}^{*}=\left(\sigma^{*}\right)^{2} / E$, where $E$ is the Young modulus of the material. The volume $V^{*}$ influencing fatigue crack initiation (i.e. the volume where microdamage can initiate) can be defined around the fatigue critical point $C_{i}$ (where $W_{\mathrm{g}}$ has a local maximum) by 
the following expression:

$$
\begin{aligned}
V^{*}\left(C_{i}\right)= & \text { \{points } M(x, y, z) \text { around } C_{i} \text { so that } \\
& \left.W_{\mathrm{g}}(M) \geq W_{\mathrm{g}}^{*}\right\}
\end{aligned}
$$

\subsection{Probabilistic approach}

The failure probability defined by Weibull integrates both a volumetric approach and the threshold concept, which are in agreement with the Banvillet et al. criterion. As is said before, the fatigue crack initiation is supposed to be equivalent to the failure of the structure in this paper. In high-cycle fatigue, the appearance of a millimetric fatigue crack is a very scattered phenomenon, as brittle fracture. Contrary to ductile fracture, brittle fracture can appear when the material is in its elastic range. In high-cycle multiaxial fatigue, the crack initiation occurs with local plasticity which does not modify the macroscopic behaviour of the structure. Moreover, macroscopic stress concentrations (threads, keyseats, holes, etc.) decrease, as for brittle materials, the high-cycle fatigue strength.

The model hypothesis assuming no interaction between defects (i.e. the distance between defects is supposed to be much larger than their characteristic size) is reasonable only if we consider the initiation of fatigue crack and not the crack propagation.

Even if Weibull proposed his model to predict the failure of brittle materials under quasi-static tension, it is assumed that his mathematical formalism is able to describe fatigue crack initiation probability. Since the predictions of the deterministic volumetric energy-based fatigue criterion are in good agreement with experimental data in terms of mean values $[1,2]$, a strain work density function $g\left(W_{\mathrm{g}}\right)$ is introduced instead of the Weibull stress function:

$g\left(W_{\mathrm{g}}\right)=\left(\frac{\left\langle W_{\mathrm{g}}-W_{\mathrm{g}}^{*}\right\rangle}{W_{\mathrm{u}}}\right)^{m}$

This means that the fatigue crack initiation can be described by an energy parameter and that, in the volume $V^{*}$ influencing fatigue crack initiation, a fatigue crack can initiate if $W_{\mathrm{g}}$ is higher than the threshold value $W_{\mathrm{g}}^{*}$. Integrate the positive part of the difference $\left(W_{\mathrm{g}}-W_{\mathrm{g}}^{*}\right)$ on the whole structure is strictly equivalent to integrate this quantity on the influence volume $V^{*}$.

To take into account the multiaxiality of stresses, the Weibull stress is replaced by the strain work density per loading cycle, $W_{\mathrm{g}}$ (in each elementary volume of material). The threshold value $W_{\mathrm{g}}^{*}$ replaces the threshold stress $\sigma_{0}$ (below which there is no damage). But there is no direct analogy with the reference volume $V_{0}$ proposed by Weibull and the influence volume $V^{*}$. In fact, the reference volume is often mentioned in the literature as the volume of material where damage increases because of a defect, but its quantification is very difficult and subjective. The parameter $V_{0}$ is often combined with the scale parameter $\sigma_{\mathrm{u}}$ in the quantity $V_{0}\left(\sigma_{\mathrm{u}}\right)^{m}$ whose value (together with the slope $m$ ) is sufficient to define the Weibull model. In the proposed model hereafter, the scale parameter is called $W_{\mathrm{u}}$, with $\varphi_{\mathrm{u}}=V_{0} W_{\mathrm{u}}^{m}$. The failure probability, i.e. the probability of fatigue crack initiation in a structure of volume $V$ can be computed by:

$$
\begin{aligned}
P_{\mathrm{f}}(V, \sigma) & =1-\exp \left[-\frac{1}{V_{0}} \int_{V}\left(\frac{\left\langle W_{\mathrm{g}}-W_{\mathrm{g}}^{*}\right\rangle}{W_{\mathrm{u}}}\right)^{m} \mathrm{~d} V\right] \\
& =1-\exp \left[-\int_{V^{*}} \frac{\left(W_{\mathrm{g}}-W_{\mathrm{g}}^{*}\right)^{m}}{\varphi_{\mathrm{u}}} \mathrm{d} V\right]
\end{aligned}
$$

The uniaxial stress state is chosen as a reference so that the threshold value of the strain work density $W_{\mathrm{g}}^{*}$ can be identified from the endurance limits in fully reversed tension and in rotating bending by:

$W_{\mathrm{g}}^{*}=\frac{2\left(\sigma_{\mathrm{Tens},-1}^{\mathrm{D}}\right)^{2}-\left(\sigma_{\mathrm{RotBen},-1}^{\mathrm{D}}\right)^{2}}{E}$

Thus, for any multiaxial stress state, an equivalent (to a uniaxial stress state) elastic strain work density is defined by Eq. (12):

$W_{\mathrm{g}, \mathrm{eq}}(M)=W_{\mathrm{g}}(M) \cdot \frac{F\left(\mathrm{~d} T_{\mathrm{uniax}}, \beta\right)}{F(\mathrm{~d} T(M), \beta)}$

The function $F$ is an empirical function depending on both the triaxiality degree of stresses, $\mathrm{d} T(M)$, and a material dependent parameter $\beta$ (see Banvillet et al. [1,2,19] for details). The function $F$ is representative of the material sensitivity to the stress triaxiality and is given by:

$$
\begin{aligned}
& F(\mathrm{~d} T(M), \beta) \\
& \quad=\frac{1}{1-\mathrm{d} T(M)}\left\{1-\frac{1}{\beta} \ln \left[1+\mathrm{d} T(M) \cdot\left(\mathrm{e}^{\beta}-1\right)\right]\right\}
\end{aligned}
$$

The parameter $\mathrm{d} T(M)$ is the ratio between the given elastic strain work density due to the spherical part of the stress and strain tensors, $W_{\mathrm{g}}^{\mathrm{sph}}$, and the total elastic strain work density $W_{\mathrm{g}}$

$\mathrm{d} T(M)=\frac{W_{\mathrm{g}}^{\mathrm{sph}}(M)}{W_{\mathrm{g}}(M)}$

where

$W_{\mathrm{g}}^{\mathrm{sph}}(M)=\frac{1}{3} \int_{T}\left\langle\operatorname{trace}\left[\sigma_{i j}(M, t)\right] \cdot \operatorname{trace}\left[\dot{\varepsilon}_{i j}^{\mathrm{e}}(M, t)\right]\right\rangle \mathrm{d} t$

The identification of the material dependent parameter $\beta$ is done from two median experimental fully reversed endurance limits: in rotating bending and in torsion on smooth specimens. As is shown in $[1,19], \beta$ is the solution of the following equation:

$$
\begin{aligned}
& \left(\frac{\sigma_{\text {RotBen },-1}^{\mathrm{D}}}{\tau_{-1}^{\mathrm{D}}}\right)^{2}-3\left[1-\frac{1}{\beta} \ln \left(1+\frac{1-2 \nu}{3}(\exp (\beta)-1)\right)\right] \\
& \quad=0
\end{aligned}
$$

For any stress state (uniaxial or multiaxial), the fatigue strength distribution for a structure with a volume $V$ submitted 


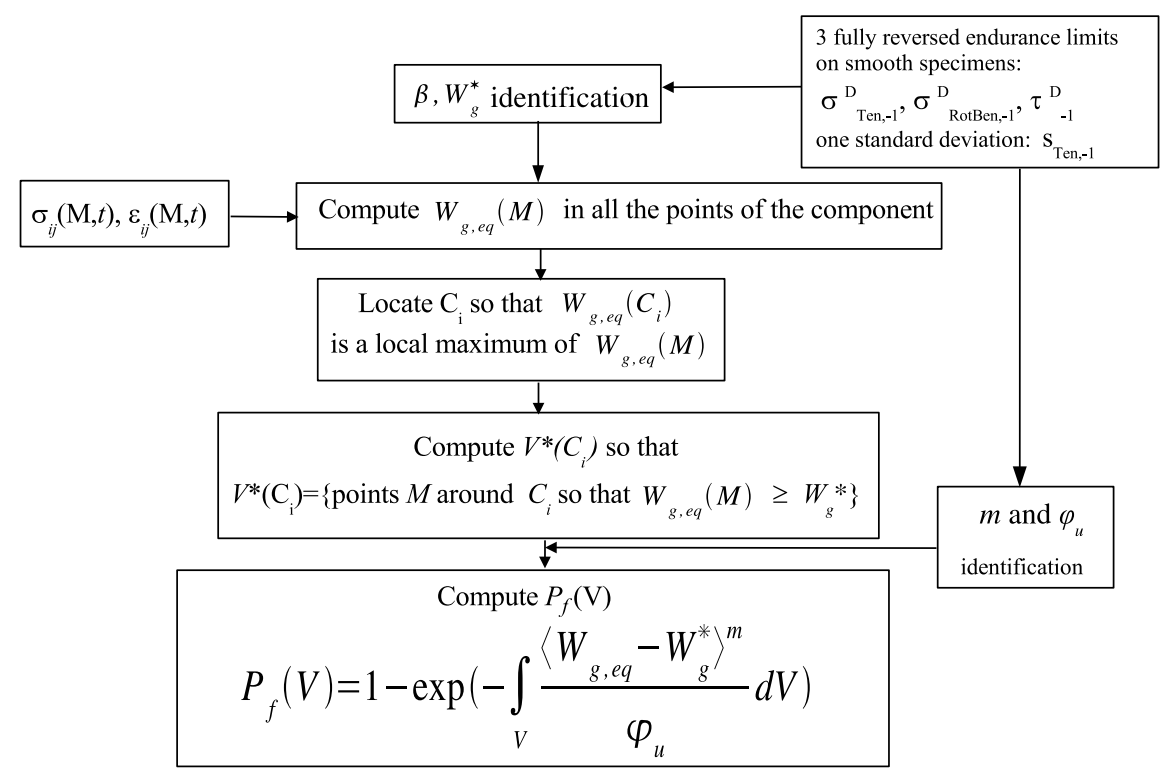

Fig. 1. Flow-chart of the proposed probabilistic model to estimate the distribution of the multiaxial fatigue strength of a component.

to a cyclic load, at a given number of cycles, can be written as follows

$P_{\mathrm{f}}(V)=1-\exp \left[-\int_{V} \frac{\left\langle W_{\mathrm{g}, \mathrm{eq}}-W_{\mathrm{g}}^{*}\right\rangle^{m}}{\varphi_{\mathrm{u}}} \mathrm{d} V\right]$

or by integrating over the influence volume:

$P_{\mathrm{f}}(V)=1-\exp \left[-\int_{V^{*}} \frac{\left(W_{\mathrm{g}, \mathrm{eq}}-W_{\mathrm{g}}^{*}\right)^{m}}{\varphi_{\mathrm{u}}} \mathrm{d} V\right]$

The two parameters $m$ and $\varphi_{\mathrm{u}}$ are identified from the experimental fully reversed endurance limit in tension (on smooth specimens) and its standard deviation $s_{\text {Tens, }-1}$. The stair case method [21] has been used in our experiments. This identification is done with the usual hypothesis (which has never been disclaimed in the literature to the authors knowledge) that the fatigue limit distribution can be described by a normal law characterized by its median and its standard deviation [22,23]. The slope parameter $m$ is identified from the experimental probability function of the fatigue limit under fully reversed tension on smooth specimens. Its value is fitted so that, around the median endurance limit, $\sigma_{\text {Tens, }-1}^{\mathrm{D}}$, the slope of both the theoretical and the experimental repartition functions should be equal.

\subsection{Synoptic of the proposal}

The application of the proposed criterion on an industrial component requires a finite element analysis to compute $W_{\mathrm{g}}$ at all the points of the component from the stress and strain time history, and to compute the volume influencing fatigue crack initiation. The flowchart of the criterion is shown in Fig. 1.

\section{Comparison between predictions and experiments}

Predictions of our proposal are compared with experimental results in high-cycle multiaxial fatigue $\left(10^{6}\right.$ cycles or more) on smooth specimens $\left(K_{\mathrm{t}}=1.07\right.$, for bending and torsion specimens and $K_{\mathrm{t}}=1.05$ for tension specimens) made of five materials: annealed Ti-6Al-4V titanium alloy (from Delahay [17]), quenched and tempered 30NiCrMo16 steel (from Froustey et al. [24]), quenched and tempered 35CrMo4 steel (from Palin-Luc [14]), annealed C20 steel (from Barrault et al. [25]) and SG cast iron, EN-GJS800-2 (from Bennebach [26] and Palin-Luc [14]). All the endurance limits have been obtained through the stair-case method with at least 15 specimens. The main mechanical characteristics (the deterministic parameters $\sigma^{*}, \beta, W_{\mathrm{g}}^{*}$ and the probabilistic parameters $m$ and $\varphi_{\mathrm{u}}$ ) of each material are given in Table 1 . Their values have been obtained both from three median endurance limits (for $10^{6}$ cycles or more in tension, in rotating bending and in torsion; see italic values in Table 2) and from the experimental standard

Table 1

Mechanical characteristics of the tested materials and their parameters for the proposed model

\begin{tabular}{|c|c|c|c|c|c|c|c|c|c|c|}
\hline Material & $E(\mathrm{GPa})$ & $\nu$ & $\sigma_{\mathrm{Y}_{0.2}}(\mathrm{MPa})$ & $R_{\mathrm{m}}(\mathrm{MPa})$ & $A(\%)$ & $\sigma^{*}(\mathrm{MPa})$ & $\beta$ & $W_{\mathrm{g}}^{*}\left(\mathrm{MJ} / \mathrm{m}^{3}\right)$ & $\varphi_{\mathrm{u}}\left(\mathrm{MJ} / \mathrm{m}^{3}\right)^{m}$ & $m$ \\
\hline Ti-6Al-4V & 110 & 0.3 & 980 & 1090 & 18 & 563 & 1.79 & 0.125 & $1.115 \times 10^{14}$ & 2.6 \\
\hline 30NiCrMo16 & 200 & 0.29 & 950 & 1200 & - & 441 & 0.963 & 0.681 & $1.55 \times 10^{16}$ & 2.8 \\
\hline $35 \mathrm{NiCrMo} 4$ & 200 & 0.29 & 1019 & 1123 & 13 & 534 & 1.33 & 0.140 & $2.775 \times 10^{17}$ & 5.4 \\
\hline $\mathrm{C} 20$ & 210 & 0.3 & 350 & 520 & 24 & 230 & -1.456 & 0.115 & $2.473 \times 10^{16}$ & 3.2 \\
\hline EN-GJS800-2 & 165 & 0.275 & 462 & 795 & 9 & 204 & 3.09 & 0.25 & $1.067 \times 10^{16}$ & 3.1 \\
\hline
\end{tabular}


Table 2

Median experimental endurance limits $\left(P_{\mathrm{f}}=0.5\right)$ and standard deviation $(s)$ on smooth specimens at $10^{6}$ or $10^{7}$ cycles (in MPa) and relative error of prediction (REP) values $(\%)$ for the proposed model

\begin{tabular}{|c|c|c|c|c|c|c|c|c|}
\hline Material & Load type & $\sigma_{\mathrm{a}}^{D}$ & $\sigma^{\mathrm{D}}$ & $\tau_{\mathrm{a}}^{\mathrm{D}}$ & $\bar{\tau}^{D}$ & $s$ & $\phi\left({ }^{\circ}\right)$ & $\operatorname{REP}(\%)$ \\
\hline Ti-6Al-4V & Tens & 583 & 0 & - & - & 17 & - & - \\
\hline Ti-6Al-4V & Rot. B. & 602 & 0 & - & - & 34 & - & - \\
\hline Ti-6Al-4V & Tors & - & - & 411 & 0 & 27 & - & - \\
\hline Ti-6Al-4V & Pl. B. & 652 & 0 & - & - & 20 & - & -1.8 \\
\hline Ti-6Al-4V & Pl. B. + To & 442 & 0 & 255 & 0 & 47 & 0 & -14.2 \\
\hline Ti-6Al-4V & Pl. B. + To & 567 & 0 & 328 & 0 & 17 & 90 & 10.9 \\
\hline 30NiCrMo16 & Tens & 560 & 0 & - & - & 19 & - & - \\
\hline 30NiCrMo16 & Rot. B. & 658 & 0 & - & - & 13 & - & - \\
\hline 30NiCrMo16 & Tors & - & - & 428 & 0 & 14 & - & - \\
\hline 30NiCrMo16 & Pl. B & 690 & 0 & - & - & 63 & - & -9.3 \\
\hline 30NiCrMo16 & Tens & 235 & 745 & - & - & 54 & - & 10.2 \\
\hline 30NiCrMo16 & Tens & 251 & 704 & - & - & - & - & 11.1 \\
\hline 30NiCrMo16 & Tens & 527 & 222 & - & - & 35 & - & 2.3 \\
\hline 30NiCrMo16 & Pl. B & 558 & 428 & - & - & 24 & - & -11.2 \\
\hline 30NiCrMo16 & Pl.B.+ To. & 470 & 299 & 261 & 0 & 19 & 90 & -8.5 \\
\hline 30NiCrMo16 & Pl.B.+To. & 584 & 281 & 142 & 0 & 34 & 0 & -11.3 \\
\hline 30NiCrMo16 & Rot.B. + To. & 474 & 294 & 265 & 0 & 50 & 45 & -7.6 \\
\hline 35NiCrMo4 & Tens & 558 & 0 & - & - & 16 & - & - \\
\hline $35 \mathrm{NiCrMo} 4$ & Rot. B. & 581 & 0 & - & - & 23 & - & - \\
\hline 35NiCrMo4 & Tors & - & - & 384 & 0 & - & - & - \\
\hline 35NiCrMo4 & Pl. B & 620 & 0 & - & - & 20 & - & 3.1 \\
\hline $\mathrm{C} 20$ & Tens & 273 & 0 & - & - & - & - & - \\
\hline $\mathrm{C} 20$ & Rot. B. & 310 & 0 & - & - & - & - & - \\
\hline $\mathrm{C} 20$ & Tors & - & - & 186 & 0 & - & - & - \\
\hline $\mathrm{C} 20$ & Pl. B & 332 & 0 & - & - & - & - & -3.9 \\
\hline $\mathrm{C} 20$ & Pl. B. + To. & 246 & 0 & 138 & 0 & - & 0 & 0 \\
\hline $\mathrm{C} 20$ & Pl. B. + To. & 246 & 0 & 138 & 0 & - & 45 & 0 \\
\hline $\mathrm{C} 20$ & Pl.B. + To & 264 & 0 & 148 & 0 & 16 & 90 & 6.8 \\
\hline EN-GJS800-2 & Tens & 245 & 0 & - & - & 6 & - & - \\
\hline EN-GJS800-2 & Rot. B. & 294 & 0 & - & - & 13 & - & - \\
\hline EN-GJS800-2 & Tors & - & - & 220 & 0 & 3.2 & - & - \\
\hline EN-GJS800-2 & Pl. B. & 280 & 0 & - & - & 11 & - & -6.4 \\
\hline EN-GJS800-2 & Pl.B. + To & 185 & 225 & - & - & - & - & -18.5 \\
\hline EN-GJS800-2 & Pl.B. + To & 199 & 0 & 147 & 0 & 4.5 & 0 & -8.5 \\
\hline EN-GJS800-2 & Pl.B. + To & 245 & 0 & 142 & 0 & 8 & 90 & 1.2 \\
\hline EN-GJS800-2 & Pl.B. + To & 228 & 0 & 132 & 0 & 11 & 0 & -6.1 \\
\hline
\end{tabular}

Italic values were used to identify the material parameters.
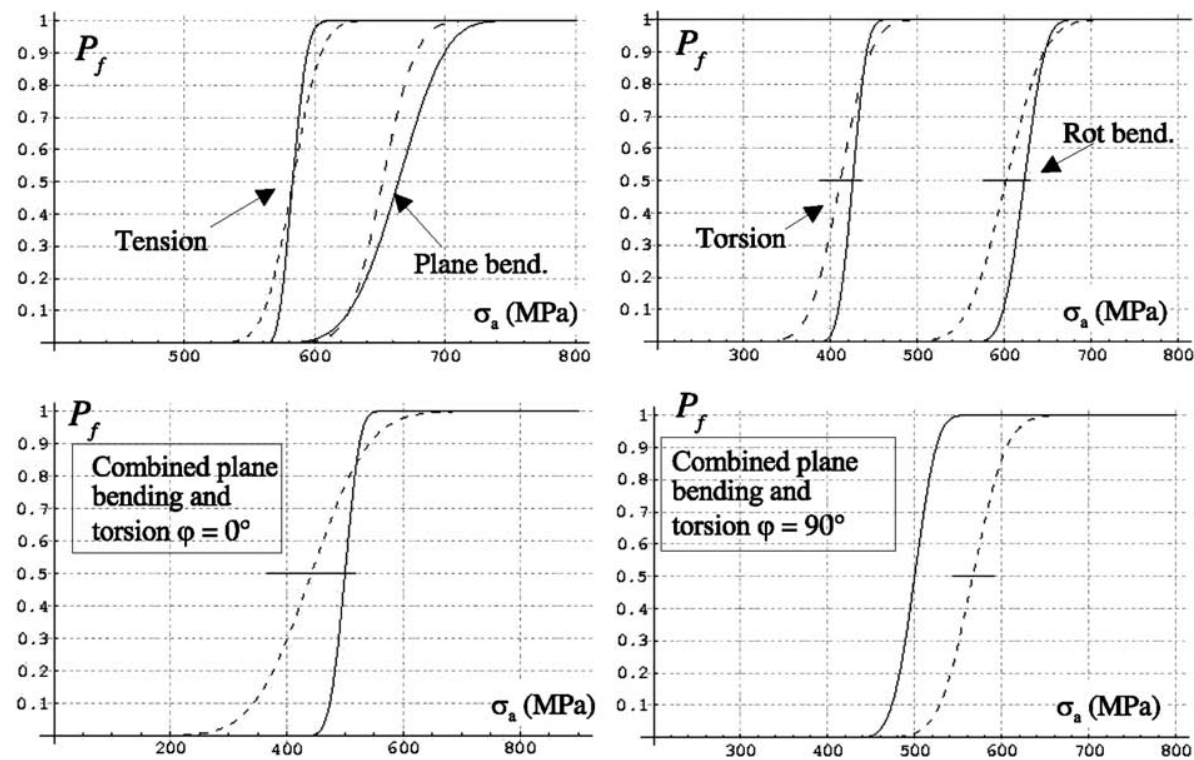

Fig. 2. Fatigue strength probability distributions $P_{\mathrm{f}}$ versus stress amplitude $\sigma_{\mathrm{a}}$ for smooth specimens in Ti-6Al-4V alloy. For combined plane bending and torsion: $R_{\sigma}=-1, \sigma_{\mathrm{a}} / T_{\mathrm{a}}=1.732$ (full line: theoretical predictions, dashed line: experimental distributions). 
deviation of the endurance limit in tension on smooth specimens.

The fatigue strength probability distribution at $2 \times 10^{6}$ cycles is computed as a function of the stress amplitude. The model predictions are compared with the experimental fatigue strength distributions which were identified from experimental fatigue data as normal distributions [22]. All the fatigue test results under different load conditions are detailed in Table 2. The predictions are in good agreement with experiments for the five materials being examined. Also, the different types of loading being considered can be distinguished. Figs. 2-6 show the probability distribution of the fatigue strength at $2 \times 10^{6}$ cycles against the stress amplitude. In these figures, the horizontal segments for $P_{\mathrm{f}}=0.5$ represent the confidence intervals at $95 \%$ associated with the experimental endurance limit. This confidence interval was computed as proposed by Dixon and Mood [21]. Note that knowing the experimental endurance limit in tension with $P_{\mathrm{f}}=0.5$ and its standard deviation, the model is capable of fully describing all the statistical behaviour of the specimens. The predicted median endurance limits are included in the $95 \%$ confidence interval when this interval can be estimated.

Furthermore, for fully reversed combined plane bending and torsion with or without phase shift, the predicted medians are in

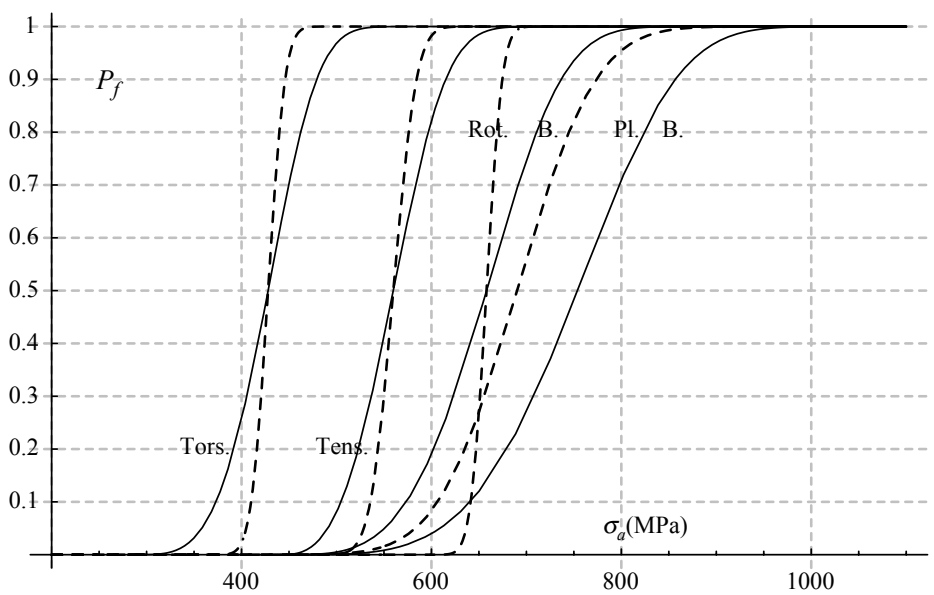

(a) Fully reversed simple loadings

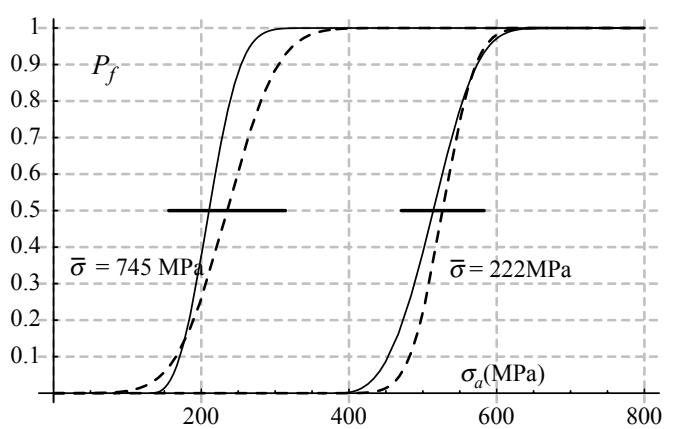

(b) Tension with mean stress

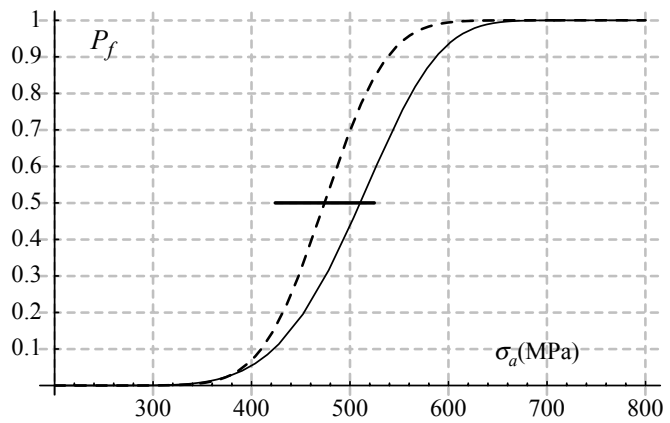

(d) Fully reversed combined plane bending and torsion, $\sigma_{a} / \tau_{a}=1.79 ; \phi=45 \mathrm{deg}$

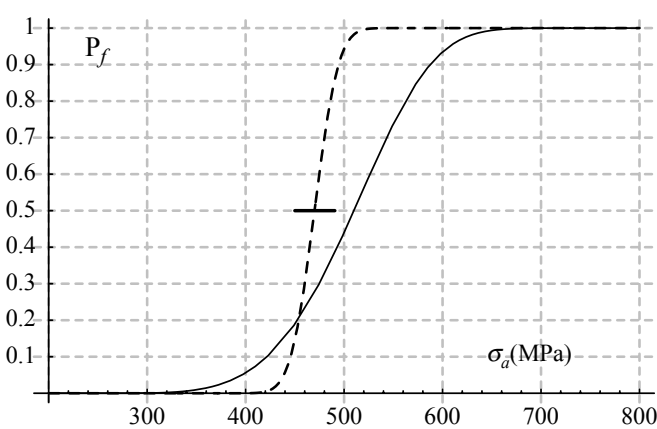

(c) Fully reversed combined plane bending and torsion, $\sigma_{a} / \tau_{a}=1.8 ; \phi=0 \mathrm{deg}$

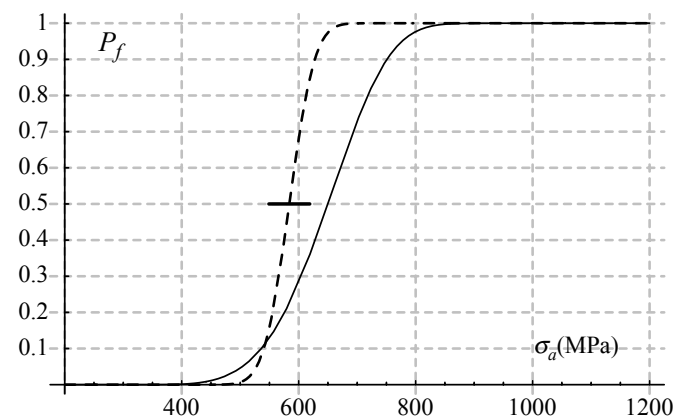

(e) Fully reversed combined plane bending and torsion, $\sigma_{a} / \tau_{a}=4.1 ; \phi=0 \mathrm{deg}$

Fig. 3. Fatigue strength probability distributions $P_{\mathrm{f}}$ versus stress amplitude $\sigma_{\mathrm{a}}$ for smooth specimens in $30 \mathrm{NiCrMo} 16$ steel (full line: theoretical predictions, dashed line: experimental distributions). 


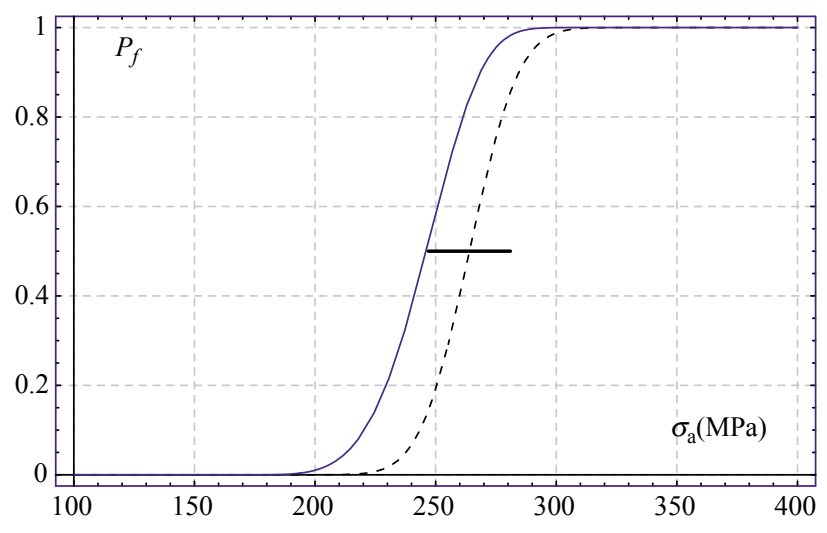

Fig. 4. Fatigue strength probability distributions $P_{\mathrm{f}}$ versus stress amplitude $\sigma_{\mathrm{a}}$ for smooth specimens in $\mathrm{C} 20$ steel loaded under fully reversed combined plane bending and torsion with a phase-shift of $90^{\circ}$ and $\sigma_{\mathrm{a}} / \tau_{\mathrm{a}}=1.78$ (full line: theoretical predictions, dashed line: experimental distributions).

good agreement with experiments. The model is not sensitive to the phase shift in combined plane bending and torsion. But it is phase-shift sensitive under biaxial tension. Indeed, $W_{\mathrm{g}}$ is phase dependent under this loading [1]. In Fig. 2, for bending and torsion with a phase shift of $90^{\circ}$, the experimental endurance limit and the standard deviation have been estimated with a set of specimens with a different roughness. This can explain why the model prediction is not in the associated confidence interval at $95 \%$.

To prove the efficiency of the proposed model for $P_{\mathrm{f}}=0.5$, its median endurance limit predictions at $10^{6}$ cycles or more (depending on the experimental data) are compared with experimental data on smooth specimens in Table 2. In this table, the Relative Error of Prediction (REP) of the model is reported in $(\%)$. Such an error is defined as follows

$\mathrm{REP}=\frac{\sigma_{\mathrm{a}, \exp }^{\mathrm{D}}-\sigma_{\mathrm{a}, \mathrm{pred}}^{\mathrm{D}}}{\sigma_{\mathrm{a}, \exp }^{\mathrm{D}}}$ where $\sigma_{\mathrm{a}, \exp }^{\mathrm{D}}$ is the median experimental endurance limit (normal stress amplitude, except for torsion tests where it is the shear stress amplitude); $\sigma_{\mathrm{a} \text {,pred }}^{\mathrm{D}}$ is the median predicted endurance limit (normal stress amplitude, except for torsion tests where it is the shear stress amplitude). The median predictions are in very good agreement with the experimental data: the REP values are inside the interval $[-20 \%,+20 \%]$.

\section{Discussion}

\subsection{Mean value effect}

Sines [27] pointed out the low influence of the mean torsion load if the maximum shear stress is below the shear yield stress $\tau_{\mathrm{Y}}$. Fig. 7 illustrates the probability distribution of the endurance limit of smooth specimens made of Ti-6Al-4V titanium alloy for different mean shear stresses. In this figure, for a mean shear stress $\bar{\tau}=150 \mathrm{MPa}, \tau_{\max }\left(P_{\mathrm{f}}=0.5\right)$ is equal to $560 \mathrm{MPa}$; this value of $\tau_{\max }$ is equal to the shear yield stress $\tau_{\mathrm{Y}}$ given in the literature for this titanium alloy. The predicted endurance limit is $7 \%$ lower than the endurance limit in fully reversed torsion. The proposal is in good agreement with Sines [27]. Moreover, Fig. 8 shows that, when the shear yield stress $\tau_{\mathrm{Y}}$ is exceeded, the model is sensitive to the effect of the mean shear, as is confirmed by Smith [28]. The proposal also predicts the effect of positive mean normal stresses, $\bar{\sigma}$, as is shown in Fig. 3b.

One drawback of the proposed probabilistic model is to consider positive and negative normal mean stresses in the same way, and this leads to conservative predictions because it is well-known from experiments that negative normal mean stresses increase the fatigue strength of components. The model can thus be used to design without failure risk. A possible way to improve this aspect is to separate the strain work density given to the material per loading cycle $W_{\mathrm{g}}$, in two parts: one corresponding to the spherical part $W_{\mathrm{g}}^{\mathrm{sph}}$ of the stress

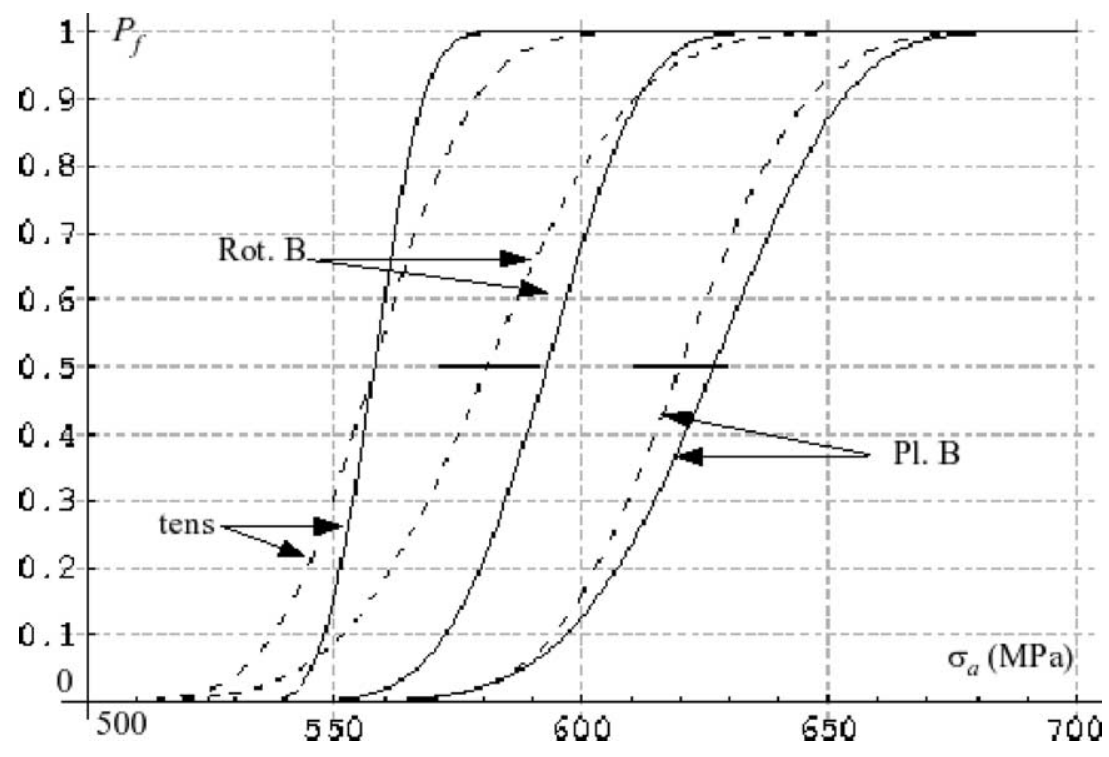

Fig. 5. Fatigue strength probability distributions $P_{\mathrm{f}}$ versus stress amplitude for smooth specimens in 35CrMo4 steel (full line: theoretical predictions, dashed line: experimental distributions). 


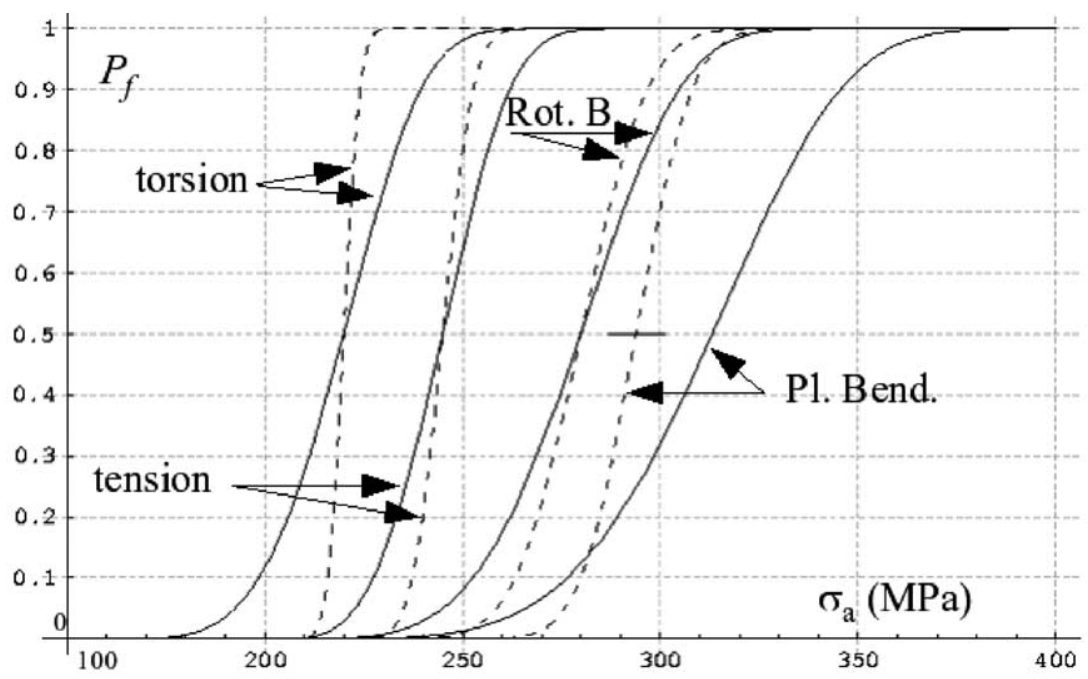

(a) Fully reversed simple loadings
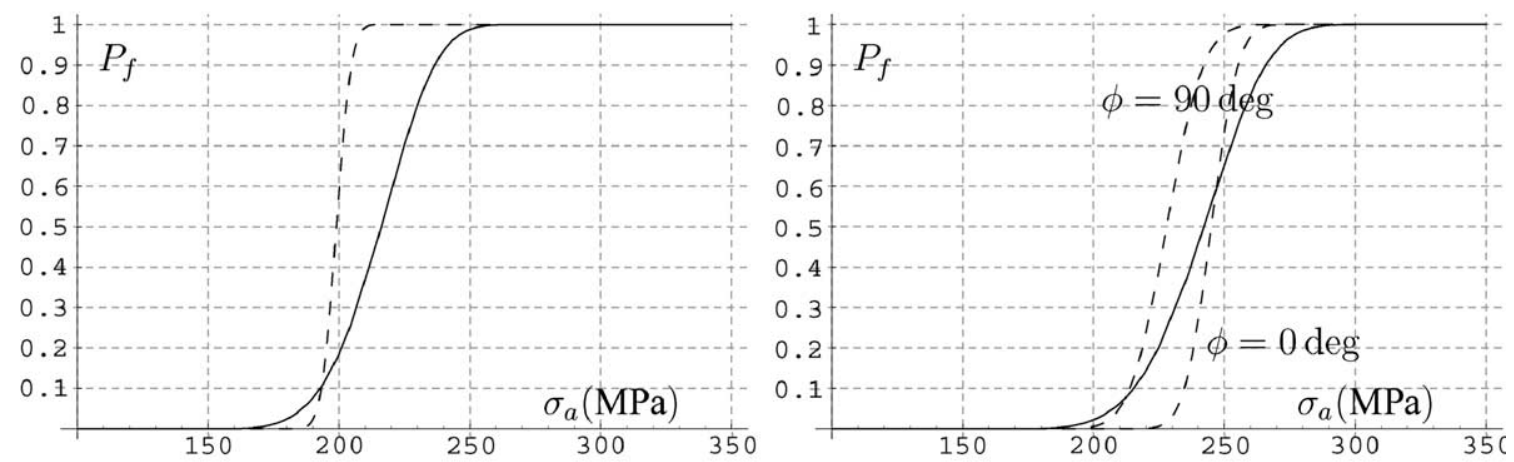

(b) Fully reversed combined plane bending and torsion, $\sigma_{a} / \tau_{a}=1.35, \phi=0 \mathrm{deg}$

(c) Fully reversed combined plane bending and torsion, $\sigma_{a} / \tau_{a}=1.732$

Fig. 6. Fatigue strength probability distributions $P_{\mathrm{f}}$ versus stress amplitude for smooth specimens in EN-GJS800-2 SG cast iron (full line: theoretical predictions, dashed line: experimental distributions).

and strain tensors, the other one corresponding to the deviatoric part of these tensors $W_{\mathrm{g}}^{\mathrm{dev}}: W_{\mathrm{g}}=W_{\mathrm{g}}^{\mathrm{sph}}+W_{\mathrm{g}}^{\mathrm{dev}}$, and to modify the definition of $W_{\mathrm{g}}^{\text {sph }}$ to distinguish a tension hydrostatic stress state from a compression one. Future work has to be carried out in this way.

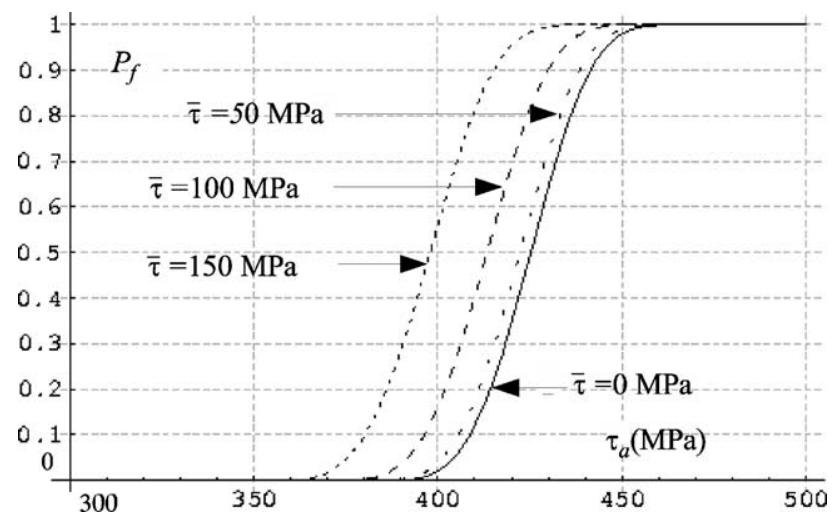

Fig. 7. Influence of the mean shear stress on the endurance limit probability distribution $P_{\mathrm{f}}$ of smooth specimens made of Ti-6Al-4V titanium alloy.

\subsection{Size effect}

In high-cycle fatigue, the size effect is often linked with the stress-strain gradient effect as was shown by Papadopoulos et al. [29]. Its effect cannot be neglected in the design of large mechanical components. A lot of studies concerning this effect have been carried out [10,29-34], but taking into account this effect in calculation methods without empirical parameter is unusual [35]. Due to the Weibull formalism, the proposed probabilistic model is able to predict this effect.

In fully reversed tension, the probability of failure before a given number of cycles for a smooth component is as follows

$P_{\mathrm{f}}\left(V, \sigma_{\mathrm{a}}\right)=1-\exp \left[-\frac{V}{\varphi_{\mathrm{u}}}\left\langle\frac{\left(\sigma_{\mathrm{a}}\right)^{2}}{E}-W_{\mathrm{g}}^{*}\right\rangle^{m}\right]$

where $V$ represents the volume of the component. For two components with different volumes, $V_{\text {ref }}$ and $V$, where $V_{\text {ref }}$ is the volume of the specimen chosen as a reference (for example, to identify the parameters of the model from laboratory tests), the last equation allows us to compute, for the same probability, the evolution of the ratio of the fatigue limits in 


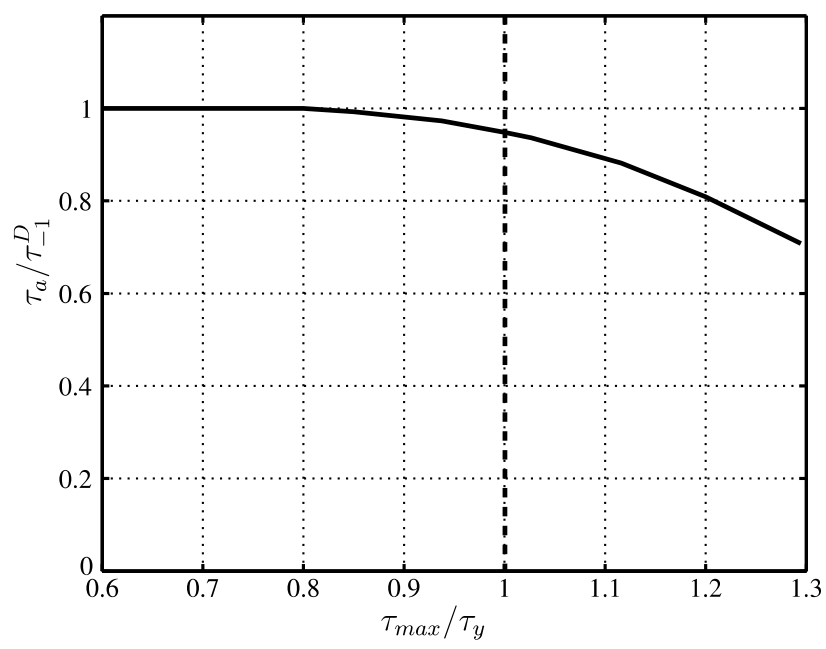

Fig. 8. Influence of the maximum shear stress on the median endurance limit predicted by the model for smooth specimens in $\mathrm{Ti}-6 \mathrm{Al}-4 \mathrm{~V}$ under torsion.

tension $\left(R_{\sigma}=-1\right), \sigma_{\mathrm{a}, \text { tens,ref }}^{\mathrm{D}}$ and $\sigma_{\mathrm{a} \text {,tens }}^{\mathrm{D}}$ :

$$
\begin{aligned}
\frac{\sigma_{\mathrm{a}, \text { tens }}^{\mathrm{D}}}{\sigma_{\mathrm{a}, \text { tens,ref }}^{\mathrm{D}}}= & \frac{1}{\sigma_{\mathrm{a}, \text { tens,ref }}^{\mathrm{D}}} \\
& \times \sqrt{\left[\left(\frac{V_{\text {ref }}}{V}\right)^{1 / m}\left(\sigma_{\mathrm{a}, \text { tens,ref }}^{\mathrm{D}^{2}}-\sigma^{*^{2}}\right)+\sigma^{*^{2}}\right]}
\end{aligned}
$$

The evolution of the ratio $\sigma_{\mathrm{a} \text {,tens }}^{\mathrm{D}} / \sigma_{\mathrm{a}, \text { tens,ref }}^{\mathrm{D}}$ against $V / V_{\text {ref }}$ is plotted in Fig. 9 for the annealed $\mathrm{Ti}-6 \mathrm{Al}-4 \mathrm{~V}$ titanium alloy presented before. This figure shows that the ratio $\sigma_{\mathrm{a}, \text { tens }}^{\mathrm{D}} /$ $\sigma_{\mathrm{a}, \text { tens,ref }}^{\mathrm{D}}$ presents a horizontal asymptotic value $\sigma_{\mathrm{a}, \text { tens }}^{\mathrm{D}} / \sigma_{\mathrm{a} \text {,tens,ref }}^{\mathrm{D}}$ $=\sigma^{*} / \sigma_{\mathrm{a}, \text { tens,ref }}^{\mathrm{D}}=0.965$ (for Ti-6Al-4V, $\sigma_{\mathrm{a} \text {,tens,ref }}^{\mathrm{D}}=583 \mathrm{MPa}$ and $\sigma^{*}=563 \mathrm{MPa}$ ). The existence of this asymptote is linked with the concept of the threshold stress $\sigma^{*}$. This figure also illustrates that the model predictions are qualitatively in agreement with those found in the literature [32,33,36]. Unfortunately, the authors did not found experimental data on specimens with very different sizes, but under the same conditions (specimen roughness, low residual stresses, machining conditions).

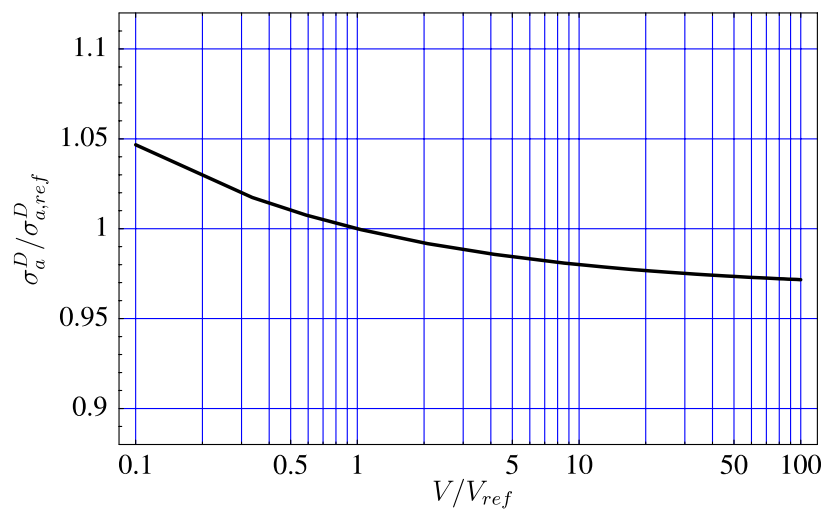

Fig. 9. Prediction of the size effect on the endurance limit in tension $\left(R_{\sigma}=-1\right)$ for smooth specimens of Ti-6Al-4V. Diameter of the reference specimens is equal to $7.98 \mathrm{~mm}$.

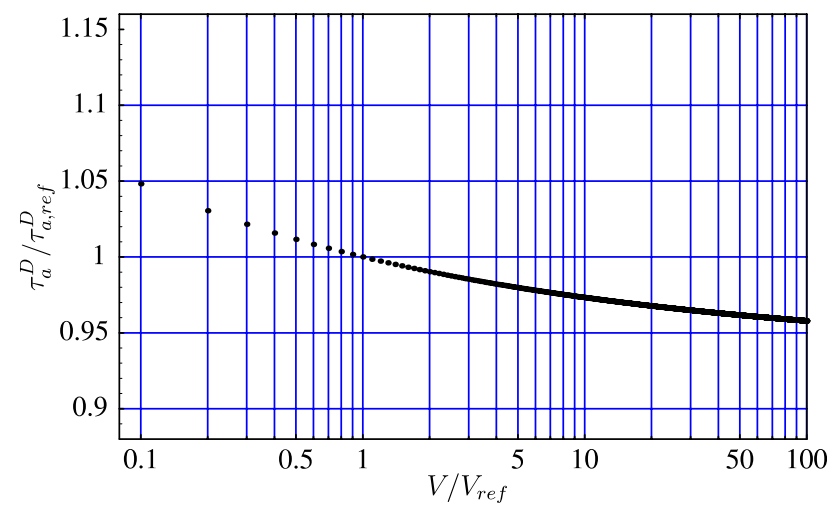

Fig. 10. Prediction of the size effect on the endurance limit in torsion $\left(R_{\sigma}=-1\right)$ of smooth specimens of Ti-6Al-4V. Diameter of the reference specimens is equal to $7.98 \mathrm{~mm}$.

For others loadings, it is not possible to express analytically the stress ratio against the others parameters. In torsion $\left(R_{\sigma}=-1\right)$, the endurance limit of a specimen with a volume $V$ can be determined from the following equation

$\frac{V}{V_{\text {ref }}}=\left(\frac{\tau_{\mathrm{a}}^{\mathrm{D}}}{\tau_{\mathrm{a}, \text { ref }}^{\mathrm{D}}}\right)^{4}\left(\frac{\left(\tau_{\mathrm{a}, \text { ref }}^{\mathrm{D}}\right)^{2} 2 F\left(\mathrm{~d} T_{\text {uniax }}, \beta\right)(1+\nu) / E-\left(\sigma^{*}\right)^{2}}{\left(\tau_{\mathrm{a}}^{\mathrm{D}}\right)^{2} 2 F\left(\mathrm{~d} T_{\text {uniax }}, \beta\right)(1+\nu) / E-\left(\sigma^{*}\right)^{2}}\right)^{m+2}$

where $\tau_{\mathrm{a}, \text { ref }}^{\mathrm{D}}$ represents the reference endurance limit for a specimen with the volume $V_{\text {ref. }}$ For the same probabilities, the relation linking the endurance limits $\tau_{\mathrm{a}}^{\mathrm{D}}$ and $\tau_{\mathrm{a} \text {,ref }}^{\mathrm{D}}$ against their respective volumes is given by Eq. (22). A numerical solution of Eq. (22) allows us to plot Fig. 10. This figure shows that the predicted endurance limit in torsion $\left(R_{\sigma}=-1\right)$ tends to an asymptotic value. It can be shown that the ratio $\tau_{\mathrm{a}}^{\mathrm{D}} / \tau_{\mathrm{a} \text {,ref }}^{\mathrm{D}}$ tends to $\tau^{*} / \tau_{\mathrm{a} \text {,ref }}^{\mathrm{D}}$, where $\tau^{*}$ is the shear stress in torsion $\left(R_{\sigma}=-1\right)$ for which $W_{\mathrm{g}, \mathrm{eq}}=W_{\mathrm{g}}^{*}$ :

$$
\tau^{*}=\frac{\sigma^{*}}{\sqrt{2(1+\nu) F\left(\mathrm{~d} T_{\text {uniax }}, \beta\right)}}
$$

For the annealed $\mathrm{Ti}-6 \mathrm{Al}-4 \mathrm{~V}$ titanium alloy $\tau^{*} / \tau_{\mathrm{a} \text {,ref }}^{\mathrm{D}}$ is equal to $0.934\left(\tau_{\mathrm{a} \text {, ref }}^{\mathrm{D}}=411 \mathrm{MPa}\right.$ and $\tau^{*}=384 \mathrm{MPa}$ [17]). Even if no quantitative comparisons between theoretical predictions and experiments have been done (due to the lack of fatigue data) the asymptotic trend of the two previous scaling curves is qualitatively similar to that predicted according to the stress gradient theory of Findley [37].

\section{Conclusion and prospects}

This paper presents a probabilistic model to predict the fatigue strength probability distribution of structural components in high-cycle multiaxial fatigue. The model is a combination of the Weibull formalism and the deterministic energy-based high-cycle multiaxial fatigue criterion developed by Banvillet et al. $[1,2,19]$. This proposal keeps the advantages of the volumetric criterion: the load type and the stress-strain gradient effects are taken into account. Further, such a model describes and predicts the scatter of fatigue data. The scatter predicted by the model is identified from one experimental 
standard deviation (in fully reversed tension). Predictions are in very good agreement with experiments carried out on smooth specimens made of five materials (Ti-6Al-4V titanium alloy, 30NiCrMo16 steel, 35CrMo4 steel, C20 steel and EN-GJS8002 cast iron), provided that the confidence intervals at $95 \%$ associated with the experimental median fatigue limit are considered. Moreover, the model is able to predict the size effect. To apply the proposal on industrial components with a complex geometry, a post-processor for a finite element analysis is in progress.

In the future, other comparisons between the model predictions and experimental data have to be carried out for other materials to confirm the promising results presented in this paper. A surface approach has to be studied and combined with this model to predict the surface effect (roughness) in fatigue. Also, although in the present paper the threshold stress $\sigma^{*}$ has been chosen as a deterministic parameter, it seems more reasonable to consider this threshold value as a probabilistic parameter depending on the mean stresses. The positive effect of negative mean normal stresses on the fatigue strength has to be incorporated in the model, too.

\section{References}

[1] Banvillet A, Palin-Luc T, Lasserre S. A volumetric energy based high cycle multiaxial fatigue criterion. Int J Fatigue 2003;26(8):755-69.

[2] Banvillet A, Palin-Luc T, Lasserre S, Vittori JF. Energy based high cycle multiaxial fatigue criterion depending on stress-strain distribution. In: Blom AF, editor. Fatigue 2002: eighth international fatigue congress, vol.1. Stockholm: EMAS; 2002. p. 283-90.

[3] Bomas H, Linkewitz T, Mayr P. Application of a weakest-link concept to the fatigue limit of the bearing steel SAE 52100 in a bainitic condition. Fatigue Fract Eng Mater Struct 1999;22:733-41.

[4] Hild F, Marquis D. A statistical approach to the rupture of brittle materials. Eur J Mech A/Solids 1992;11:753-65.

[5] Chantier I, Bobet V, Billardon R, Hild F. A probabilistic approach to predict the very high-cycle fatigue behaviour of spheroidal graphite cast iron structures. Fatigue Fract Eng Mater Struct 1999;23:173-80.

[6] Flacelière L, Morel F, Nadot Y. Approche probabiliste en fatigue multiaxiale polycyclique: application aux défauts de fonderie. In: Fatigue et procédés de fabrication. SF2M; 2003. Journées de printemps.

[7] Weibull W. A statistical theory of the strengh of material. R Swed Inst Eng Res 1939;(151).

[8] Weibull W. The phenomenom of rupture in solids. Proc R Swed Inst Eng Res 1939;(153):1-55.

[9] Freudenthal AM. Statistical approach to brittle materials. In: Liebowitz H, editor. Fracture, vol. 2. New York: Academic Press; 1968. p. 591-619.

[10] Bazant ZP. Size effect on structural strength: a review. Appl Mech 1999; (69):703-25.

[11] Dang-Van K, Cailletaud G, Flavenot JF, Douaron L, Lieurade HP. Criterion for high-cycle failure under multiaxial loading. In: Brown M, Miller K, editors. Biaxial and multiaxial fatigue. Sheffield: ESIS; 1989. p. 459-78.

[12] Morel F, Palin-luc T. A non-local theory applied to high cycle multiaxial fatigue. Fatigue Fract Eng Mater Struct 2002;25(7):649-65.

[13] Morel F, Palin-Luc T, Froustey C. Comparative study and link between mesoscopic and energetic approaches in high cycle multiaxial fatigue. Int J Fatigue 2001;23(4):317-27.
[14] Palin-luc T. Fatigue multiaxiale d'une fonte GS sous sollicitations combinées d'amplitude variable. PhD Thesis. ENSAM CER de Bordeaux; 1996.

[15] Palin-Luc T, Lasserre S, Bérard J-Y. Experimental investigation on the significance of the conventional endurance limit of a spheroidal graphite cast iron. Fatigue Fract Eng Mater Struct 1998;21(3):192-200.

[16] Bonnafe A. Validation d'une limite de non propagation de fissure inférieure à la limite d'endurance conventionnelle d'une fonte GS. Master's Thesis. ENSAM CER de Bordeaux; 1998.

[17] Delahay T. Développement d'une méthode probabiliste de calcul en fatigue multiaxiale prenant en compte la répartition volumique des contraintes. PhD Thesis, Université Bordeaux 1, France; 2004. 247 p.

[18] Palin-Luc T, Lasserre S. An energy based criterion for high cycle multiaxial fatigue. Eur J Mech A/Solids 1998;17(2):237-51.

[19] Banvillet A. Prévision de la durée de vie en fatigue multiaxiale sous spectre de chargement réel: vers des essais accélérés. PhD Thesis, ENSAM CER de Bordeaux; 2001.

[20] Lemaitre J, Chaboche J-L. Mécanique des matériaux solides. Paris: Dunod; 1988. 544 p.

[21] Dixon WJ, Mood AM. A method for obtaining and analyzing sensitivity data. J Am Stat Assoc 1948;43:109-26.

[22] AFNOR. A 03-405: Produits Métalliques-Essais de fatigue-Le traitement statistiques des données; 1991.

[23] Bastenaire F. Etude statistique et physique de la dispersion des résistances et des endurances à la fatigue. PhD Thesis, Université de Paris; 1960.

[24] Froustey C, Lasserre S, Dubar L. Validité des critéres de fatigue multiaxiale à l'endurance en flexion-torsion. In: Fatigue des structures industrielles, IITT-International, 40 promenade Marx-Dormoy, F-93460 Gournay-sur-Marne, France; 1989. p. 126-38.

[25] Barrault J, Lasserre S. Limites de fatigue de l'acier 35cd4 en flexion rotative et en flexion plane. Rev Mécanique Matériaux et Electricité 1980; September(369):275-8.

[26] Bennebach M. Fatigue multiaxiale d'une fonte GS, influence de l'entaille et d'un traitement thermique. PhD Thesis. ENSAM CER de Bordeaux; 1993.

[27] Sines G. Behavior of metals under complex static and alternating stresses. New York: McGraw-Hill; 1959. p. 145-69.

[28] Smith J. The effects of range of stress on fatigue strength of metals. Eng Exp Station 1942;39(26):1-52.

[29] Papadopoulos IV, Panoskaltis VP. Gradient dependent multiaxial high cycle fatigue criterion. In: Fourth ICBMFF, vol. 1. St Germain en Laye: SF2M; 1994. p. 461-76.

[30] Moore HF. A study of size effect and notch sensivity in fatigue tests of steel. In: ASTM 45; 1945. p. 507-31.

[31] Massonnet C. Contribution expérimentale à l'étude de l'effet de l'échelle et des entailles. Rev Universelle des Mines 1955;(9):203-22.

[32] Pavan A. Contribution aux calculs d'organes d'ensembles mécaniques par rapport à la limite de fatigue. Explication des principaux facteurs. $\mathrm{PhD}$ Thesis, Université de Reims, Reims, France; 1979.

[33] Papadopoulos IV, Panoskaltis VP. Invariant formulation of a gradient dependent multiaxial high-cycle fatigue criterion. Eng Fract Mech 1996; 55(4):513-28.

[34] Toplack G, Eichlseder W, Istan G, Heinz L. Influence of size and type of loading on $\mathrm{S} / \mathrm{N}$ curve. In: New trends in fatigue and fracture II, Hammamet, Tunisia; 2003.

[35] Palin-Luc T, Kaufmann H, Lasserre S, Sonsino CM. Prise en compte de l'influence de la distribution des contraintes et des effets d'échelle pour une utilisation pratique en fatigue. In: 18èmes Journées de Printemps de la commission Fatigue. SF2M; 1999.

[36] Brand A, Flavenot JF, Grégoire R, Tournier C. Données technologiques sur la fatigue. Publications du CETIM; 1992.

[37] Findley WN. An explanation of size effect in fatigue of metals. J Mech Eng Sci 1972;14:424-5. 